\title{
Prospects of siting a spaceport in Africa
}

\section{Sesugh Nongo* and Ngunan M. Ikpaya}

National Space Research and Development Agency,

Obasanjo Space Centre,

Km 17 Umaru Musa Yar'Adua Expressway, Abuja, Nigeria

Email: sesugh.nongo@nasrda.gov.ng

Email: ngunan.ikpaya@nasrda.gov.ng

*Corresponding author

\section{Ikpaya Ikpaya}

Centre for Satellite Technology and Development, National Space Research and Development Agency, Obasanjo Space Centre,

Km 17 Umaru Musa Yar'Adua Expressway, Abuja, Nigeria

Email: ikpaya.ikpaya@cstd.nasrda.gov.ng

\begin{abstract}
Most communication satellites which drive the economy of the world today are launched and positioned on the equatorial orbit, which has the same rotational period as the Earth. Geographically, Africa is centrally positioned on the globe and is therefore a viable location for missions that require a direct launch into prograde orbit, as it can leverage this rotation to reduce the total energy required for launch. The global space launch services market is projected to reach US $\$ 30.2$ billion by 2025 , a $15 \%$ compound annual growth rate. This growth is significantly driven by a rise in space exploration activities, large scale investments by governments and private firms and increase in demand of small satellites and constellations. The African space industry players ought to adopt strategies to revive their existing spaceports or establish new ones to draw from the huge economic benefits of the growing market.
\end{abstract}

Keywords: African spaceport; launch system; satellite technology; sustainable development.

Reference to this paper should be made as follows: Nongo, S., Ikpaya, N.M. and Ikpaya, I. (2021) 'Prospects of siting a spaceport in Africa', Int. J. Aerospace System Science and Engineering, Vol. 1, No. 1, pp.35-54.

Biographical notes: Sesugh Nongo is a Chief Engineer at the National Space Research and Development Agency, Abuja, Nigeria. He has a PhD in Energy and Thermo-fluids from the Federal University of Agriculture, Makurdi. He is passionate about sustainable development initiatives for developing countries and creating impact on humanity through technology and innovation.

Ngunan M. Ikpaya is a Chief Engineer at the National Space Research and Development Agency Abuja. She has an MSc in Telecommunications with Management from the University of South Wales, Newport, UK. Her interest is energy and power electronics. 
Ikpaya Ikpaya is a Deputy Director at the National Space Research and Development Agency, NASRDA, Nigeria. He has a PhD in Remote Sensing Instrumentation from the University of Surrey. He is a recipient of the Commonwealth Rutherford Fellowship award and carried out his post-doctoral research at Surrey Space Centre, University of Surrey. He has worked in the space industry for over 19 years. His interest is developing space-borne payload instruments for various missions.

\section{Introduction}

A spaceport is a specialised ground-based facility built to launch and receive launch vehicles (LVs) (Roberts, 2019). Space exploration and satellite business were exclusive preserves of industrialised nations until early 2000 when developing nations such as Nigeria, India, South Africa, etc. ventured into launching of satellites for security and economic development. With the advent of nanotechnology, miniaturisation of satellites and related technologies, a chunk of space exploration services cost attributed to LV services has reduced drastically (de Selding, 2016).

The cost of taking a satellite into space is determined by the weight, size and the mission orbit of the satellite. The satellite weight and mission orbit directly affect consumption of LV propellant due to the thrust generated to overcome the weight, gravity pull and aerodynamic forces at lift-off. The satellite size however, is considered only when it affects other satellites to be jointly launched on-board the same LV. The weight of a $\mathrm{LV}$ is about $90 \%$ propellant while the remaining $10 \%$ make up the structure, payload and other components (Bradley, 2017). This implies that approximately $90 \%$ of the cost of launch services is attributed to the propellant. A reduction in the consumption of rocket propellant will significantly reduce the launch cost. One of the most efficient ways of reducing propellant cost and consequently launch cost is locating an appropriate launch site where the rotational speed of the Earth can be maximised during launch services (da Cás et al., 2019).

A space port located on the equatorial plane will take full advantage of the maximum Earth's rotational speed by launching eastwards. Providentially, the equatorial plane almost equally divides the African continent, Africa stands to benefit economically by utilising this advantage to harness the potential space launch market opportunities. Africa currently has two inactive spaceports located in Algeria and Kenya. With more African nations venturing into space technology and the growing demand for significant technological innovations to build low-cost vehicles, small satellites and constellations motivating the progress of the space launch program, the potential market for space exploration in the short term is promising. It has therefore become imperative for African nations to either reactivate the existing space ports or establish new ones along the equatorial planes of West and East Africa. The global space launch market was worth US $\$ 8.7$ billion in 2016, and is projected to grow by over $30 \%$ to reach US\$27.2 billion by 2025 , a $15 \%$ compound annual growth rate (Wallis, 2018). This paper contributes to knowledge by providing a preliminary analysis on the technical and economic potentials, business or investment opportunities, thereby forming a basis for further in-depth research into the feasibility and viability of siting a spaceport along the equatorial plane in Africa. It provides a platform for dialogue between the African nation(s) and 
prospective partners - space faring nations and private companies with heritage in satellite and launch services for possible collaboration, business and investment opportunities. This paper also contributes to protection of the environment and climate change mitigation through its proposal of a low fuel combustion launch along the equatorial plane, thereby saving cost. The impact of this work will provide socio-economic benefits for sustainable development, which will enable the improvement of the African economy and lives of the African people.

\section{African spaceport: a justifiable endeavour}

The African continent is plagued by a myriad of economic, political, social and environmental challenges - the question then to be answered is whether the development of a new spaceport in Africa or the upgrade or conversion of existing ones is a justifiable undertaking?

There are enormous benefits to be derived from an effective and well-managed space programme. In the 21 st century, spaceports represent critical infrastructure that create the basis for advancing space competitiveness, economic growth and technological development. An African spaceport will be a catalyst for integrating space technology into the economic, political and socio-economic development of this rising continent. The vision for the African spaceport is a dynamic space hub that leverages the emerging commercial space industry to aid the creation of sustainable growth for the entire African region (Robotham, 2012). The primary indicator for the success in this initiative will be its effectiveness to respond to the needs of users, improve Africa's global economy and the quality of life of the African people. It must be globally competitive to position Africa in the global space market, as there is a significant need in many developing countries outside Africa for such initiatives (African Union, 2019).

The justification for venturing into space exploration is the influence of space technology for sustainable development of African nations and its assurance of socio-economic benefits to improve the livelihood of the African people and catalyse industralisation (Isoun, 2008). Space science technologies and data contribute directly and indirectly towards sustainable development as it is the driving force behind most sustainable developed and developing countries. The acquisition and effective use of advanced space technologies and their attendant spin offs are assets to be used for new products and processes development in all spheres of the African continent to increase industrial productivity, create new companies, jobs and global competitive goods and services (Agboola, 2011). This will enable economic growth, reduce the cost of capital flight for African nations in satellite launch services, promote capacity building, technological advancement, and contribute to the gross development product (GDP) of the African continent.

Nations invest in space capabilities to fulfil national objectives: military success and defence strategy, leadership and prestige, development, resource management, economic growth and diversification. Economic growth and diversification are increasingly important as drivers of government space activity. Capturing a larger share of the global space economy is a desirable goal for a plethora of reasons. Space is a reliable growth industry that has proven resilient in the face of economic downturn, including the 2008 global recession (OECD, 2011). Space-enabled services boost productivity to other sectors of the economy, like agriculture, mining and all types of commerce. 


\section{History of African spaceports}

Caught in the wake of the cold war, several nations developed their national space programme as the enormous potential accrued to space science and technology was no longer contestable (Umunna and Ovie, 2014). Africa joined the space race as early as the late 1940s but is still developing capacity to launch her own satellites. Presently, with no active spaceports, African satellites are being launched from launch facilities in Russia, China, Kazakhstan, India, French Guiana and the USA (Oyewole, 2017). For instance, NigeriaSat-1 and NigComSat-1 and 1R were launched in Russia and China respectively (Ikpaya et al., 2017). This does not imply however that African spaceports have always been inactive or concerted efforts to develop capacity in rocket launch and missile programmes have not been made in Africa. Nigeria presently runs a low-profile sounding rocket program at its Centre for Space Transport and Propulsion, Epe (Oyewole, 2017).

\subsection{Algeria}

Since the beginning of the space cold war, Africa has been a major location for rocket and missile test sites from 1947 with the establishment of French Weapons Test Facility in Colomb-Bechar, Algeria, with part of the French test site also established in Reganne in 1950, where similar exercises were carried out. The test facilities at both sites had capabilities for sounding rocket launches and an additional site was built in May 1952, at Hammaquir, Algeria, by the same French Government to handle bigger rockets launches and surface to air missiles (Pike, 2011a). The facility carried out five notable satellite launches on Diamant rocket, the first non US-Soviet Union rocket that put a satellite into orbit, with payloads ranging from $15-40 \mathrm{~kg}$. The facility has been non-operational since the Algerian Government gained independence in 1967 (Pike, 2011a). Subsequently, French Space launches were moved to the Kourou Space Centre in French Guiana; Algeria inherited the launch facility from the French with the 1967 Evian Agreement (Oyewole, 2017).

\subsection{COngo, Libya}

In 1975 Orbital Transport und Raketen Aktiengesellschaft (OTRAG), a German Aerospace Company founded by Lurtz Kayser, established a launch site in Shaba, (Katanga Province), Republic of Congo formerly Zaire. OTRAG conducted three successful tests and launches in 1977 and 1978 respectively with the first commercial and low-cost LVs. However, in 1979, due to opposition from the French and the Soviet Union, the assembly and launch site was relocated to the desert in Sabha-Tawiwa, Libya (Wade, 2019). Thirteen rockets launches and 13 test missions were conducted there, between 1981 to 1982. In 1983, the Libyan Government took over the facility. Ten years went by with hardly any remarkable activity except a few test launches at the beginning, and eventually, the program was abandoned (Poole, 2020).

\subsection{Egypt}

The Jabal Hamzah Ballistic Missile Test and Launch facility is the first indigenous development of a launch site in Africa by Egyptian Scientists and Engineers in the 1950s. Their effort came after a failed attempt to acquire rocket technology from the Soviet 
Union. Successful launches with liquid fuel were undertaken in 1960, 1971 and 1973, respectively (Lewis, 2010). The facility experienced increased activity and expansion between 2001 and 2009 (NTI, 2015).

\subsection{Kenya}

The Luigi Broglio Space Centre (LBSC) formerly San Marco Equatorial Range Launch site is an Italian-owned spaceport near Malindi, Kenya, named after its founder and Italian space pioneer Luigi Broglio. Developed in the 1960s through a partnership between the Sapienza University of Rome's Aerospace Research Centre and National Aeronautics and Space Administration (NASA), the LBSC served as a spaceport for a total of 27 launches of both Italian and International Low Earth Orbit (LEO) and Geostationary Orbit (GEO) satellites between 1967 and 1988 (Space in Africa, 2019a). The Centre comprises a main offshore launch site, two secondary control platforms and a communications ground station on the mainland. After the expiration of the 2003 legislative decree that handed the Centre to the Italian Space Agency; Kenya and Italy only reached an agreement in 2016. According to Business Daily Africa, the Cabinet's decision on the signing of an 'equal status' agreement, which will allow Kenya earn 50\% of commercial yields from third-party contracts provided by the Centre such as launch services, satellite tracking and telemetry services, data acquisition, navigation, educational and training activities (Kimani, 2018) has been maintained by the Kenyan Defence and Foreign Relations Committee (Space in Africa, 2019a).

\subsection{Mauritania}

The launch platform in Nouadhibou, Mauritania was basically for the Aerobee platform, launching small unguided suborbital sounding rockets, for solar research. An aerobee rocket was launched from the facility on the 30th of June, 1973 as a result of the second longest solar eclipse (McDowell, 2017).

\subsection{South Africa}

The Denel Overberg Test Range (DOTR) established in 1988 was known as the Overberg Test Range or OTB until 2011. It is a well-established test range and flight facility specialised in aircraft and missiles systems (Pike, 2011b) in the Overberg region on the South Eastern Coast of the Western Cape near Arniston (Caravotas, 2019). It was used for launch tests of the RSA missile series until 1992. The test range provides long-range artillery tests, in flight tests on missiles and aviation systems, and is qualified to provide launch services for LEO satellites (Pike, 2011b). It also offers specialised in flights system performance measurement services to a variety of local and international clients in the aerospace industry (RP Defense, 2011).

\section{Global active spaceports}

Considering the location of active spaceports in the world as depicted in Figure 1, Africa is presently devoid of any active spaceports. 
Figure 1 Map of active spaceports in the world (see online version for colours)

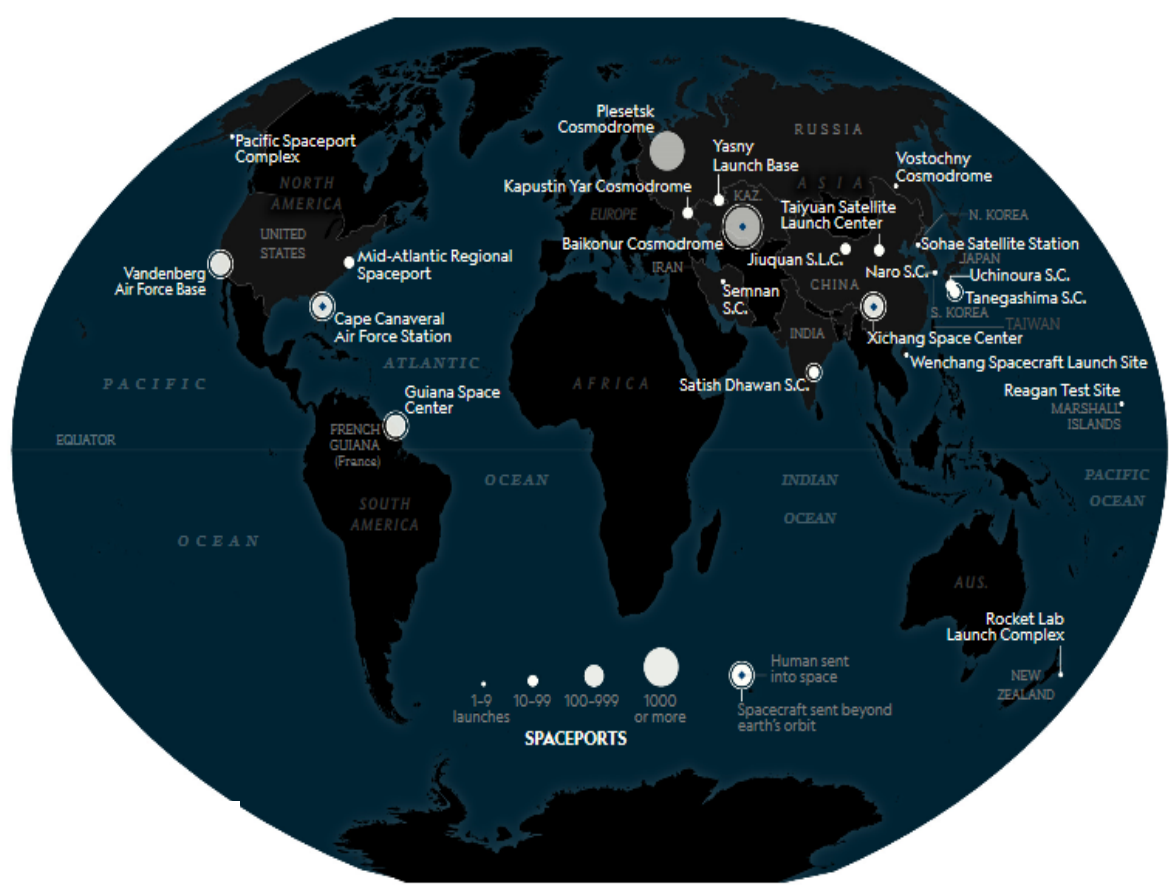

Source: Greshko (2018)

In Figure 1, most of the active spaceports are located largely above the equatorial line. Among the ones that are most active for manned missions are the Baikonur Cosmodrome in Russia, Cape Canaveral Airforce Station in US and Xichang Space Centre in China. It will be noted that these sites are located far off from the equatorial plane yet are the most active space centres in the world today.

However, spaceports that are close to the equatorial plane but relatively active today are the French Launch Control Centre Kourou at latitude $5.2^{\circ} \mathrm{N}$ longitude $52.8^{\circ} \mathrm{W}$ in Guiana, the Brazil Alcantara Launch Center at latitude $2.3^{\circ} \mathrm{S}$ longitude $44.4^{\circ} \mathrm{W}$, the Satish Dhawan Space Centre off the Indian coast at latitude $13.4^{\circ} \mathrm{N}$ longitude $80.2^{\circ} \mathrm{E}$ and Reagan Test Site in the Pacific Ocean at Federal Republic of Marshall Island located at latitude $7.7^{\circ} \mathrm{N}$ and longitude $7.1^{\circ} \mathrm{E}$.

It is noteworthy that most of the active and relatively active spaceports are located away from the equator, this could be due to the sensitivity of space exploration within territorial bounds, thereby denying them utilisation of the advantages of the equatorial plane locations, an edge the African continent has.

Today, space technology is no longer the sole business of respective states governments but involves the private sector as well. Consequently, the commercialisation of space exploration technology will be optimised when launch services cost is reduced. A spaceport located around the equator is one of such ways to achieve this feat. 


\section{The Earth equatorial plane launch potentials}

The Earth is a sphere that spins eastward along its north and south poles at a speed of $1,675 \mathrm{kmph}$. The centripetal force of the Earth's rotation causes a bulge on its surface at the equator. This bulge, the biggest radius of the Earth from its lateral centre, is about 6,378.1 km (Sellers, 2004).

$$
F=m R\left(\frac{2 \pi}{T}\right)^{2}
$$

The centripetal force, $F$, as depicted in equation (1), is proportional to the product of the mass of the body and its radius. However, the force is inversely proportional to the period of its rotation. With $m$ as the mass of the Earth, $T$ as the period of the Earth's rotation and $R$, the radius of the Earth, is the distance from the axis of rotation of the Earth to any point on the surface of the Earth (Sellers, 2004).

From equation (1), it can be observed that the farthest distance R from the Earth's centre to its surface which is possibly at the equator will yield the highest force of rotation; inferring that spaceports located at the equator will naturally take advantage of the Earth's inertia due to its eastward rotation. Consequently, the equivalence of linear velocity (V) at the equatorial surface as a result of the Earth's rotation is as shown in equation (2).

$$
V=\omega R=\frac{2 \pi}{T} R
$$

If $R$ is the radius of the Earth at the equator, it implies that the equatorial plane has the greatest velocity potential for orbital launches round the Earth.

Providentially, the equatorial line divides the African continent in almost two halves, taking advantage of this benefit, therefore to establish a spaceport at or close to the equator will maximise the benefit of the Earth's rotational speed.

\section{Orbital analysis of equatorial spaceports}

Most rockets are launched eastwards taking advantage of the Earth's rotational speed. Figure 2 illustrates the equatorial view of orbital plane changes of a spacecraft launched at higher latitude to a gradual orbital plane change to an equatorial orbit.

These manoeuvres can also be done in the reverse direction, from the equatorial orbital plane to the polar planes or the desired orbital inclination. Rocket launches made eastward of a spaceport utilise the velocity potentials of the latitude of that spaceport, and also the orbital inclination (plane) of that site. Launches made curving eastward at Baikonur Comosdrone on latitude $45.9^{\circ}$ in Russia attains an orbital inclination of same latitude and maintains the orbital plane of that inclination. Consequently, spacecraft launches for remote sensing are better launched at high orbital inclination and altitudes for more area coverage of the Earth. However, an equatorial spaceport launch of high orbital plane still has more Earth velocity potential than spaceports at higher latitudes. Equation (3) is the Earth's velocity expression, V at any latitude. This demonstrates the advantage of equatorial launch sites over higher altitude ones. Figure 3 depicts the 
Earth's rotational radius at various latitudes and shows how the Earth's rotational radius reduces at respective latitudes towards the poles.

Figure 2 Equatorial view of higher latitude transfer orbits to near equatorial plane (see online version for colours)

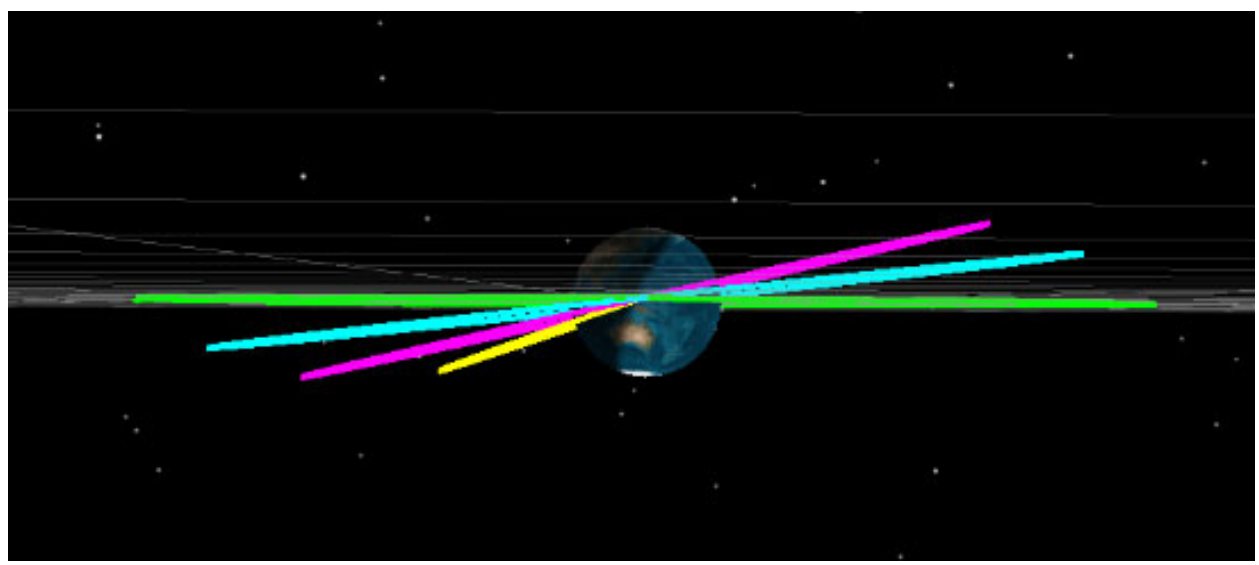

Figure 3 Schematics of the Earth's rotational axis and radius (see online version for colours)

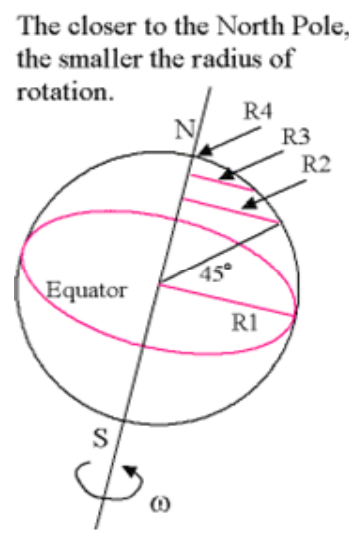

Equation (3) estimates the Earth's velocity at the respective radii of the Earth as shown in Figure 3 as $R_{1}, R_{2}, R_{3}, R_{4}$ and $\theta$ is the respective latitude in degrees

$$
V=\frac{2 \pi}{T} R_{1} \cos (\theta)
$$

It is observed from equation (3) that the Earth's natural velocity vector is highest when at latitude $0^{\circ}$ and none at $90^{\circ}$, given that every other parameter in the equation is constant. Furthermore, to demonstrate the advantage of an equatorial launch over higher latitudes ones, consider launching for inclination orbit of $\theta$ at the equator. The equatorial natural horizontal velocity vector utilised during launch will be the same with the natural Earth velocity when launching vertical at higher latitudes locations. With $\mathrm{V}$ as the natural velocity vector utilised at respective latitudes, Figure 4 shows the velocity vector values with regards to different Earth's launch latitudes. 
Figure 4 Graph of Earth's surface velocity as it varies with latitudes

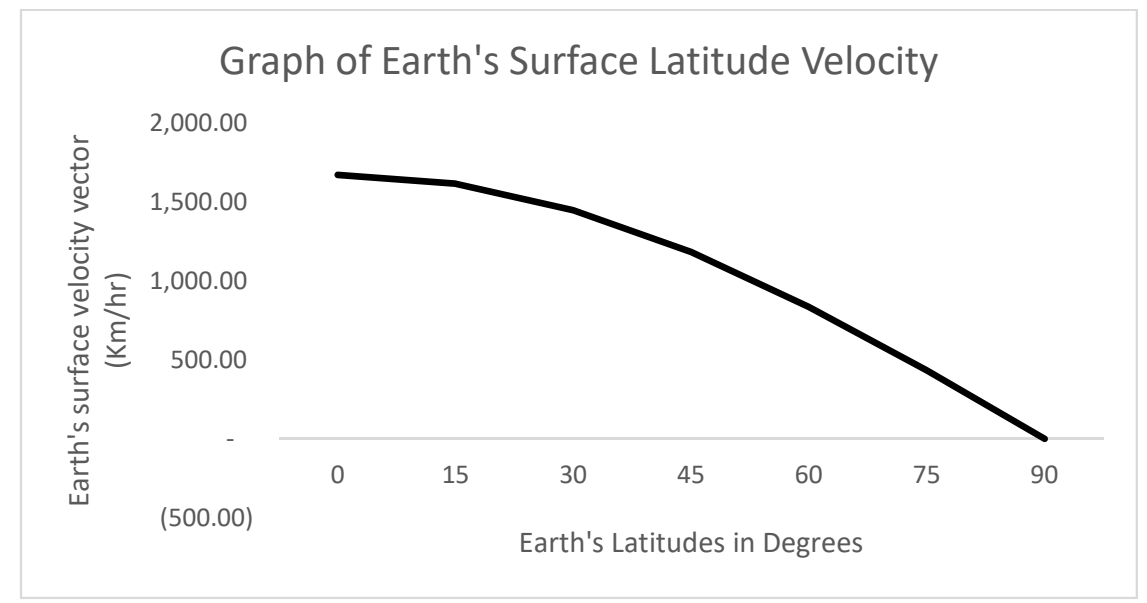

It is also interesting to note that, GEOs do not require orbit inclination and therefore suitable for launches at the equatorial spaceports that gives greater boost in Earth's velocity. These facts in Figure 4 put forward empirical evidence for establishment of a spaceport at the equatorial region for both LEO and GEO.

Figure 5 Schematics of orbital plane change (see online version for colours)

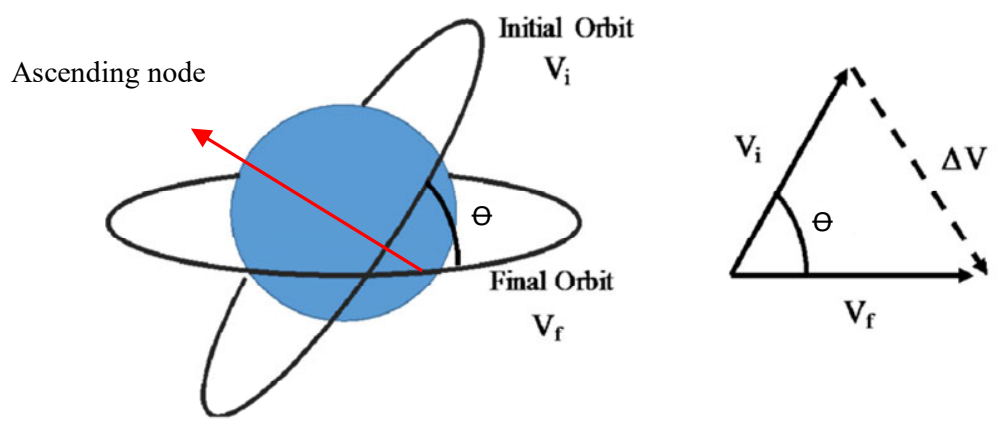

In the event of orbital plane change of launched spacecraft, the plane change is best achieved at the point of ascending and descending nodes in the orbit. The ascending and descending nodes are both located at the equatorial orbit as shown in Figure 5. Though the change in velocity due to orbital plane change is quite huge as shown in equation (4), it can be achieved in bits until the required orbital plane is attained. The spacecraft's change in velocity for an orbital plane change is determined by the initial orbital velocity and the angle of inclination of the spacecraft.

$$
\Delta V=\frac{1}{2} V_{\text {initial }} \text { Sine }\left(\frac{\theta}{2}\right)
$$

This equation shows that the greater the angle and the initial velocity, the greater the change in velocity required to change the spacecraft's orbital plane (Bate et al., 1971). Due to the amount of fuel required for orbital plane change as seen in equation (4), a 
satellite's velocity at higher altitude orbits or apogees are lower in magnitude than low altitude orbits or perigees. Therefore, less fuel consumption is required to change orbit at apogees or higher altitudes using the cosine rule as shown in equation (5). The utilisation of Hoffman's transfer orbit to achieve this orbital manoeuvre is highly required for the orbital plane change, though this is an after ground launch exercise but necessary for change in velocity determination (Delta $\mathrm{V}$ ) for mission planning.

$$
\Delta V=\sqrt{V_{i}^{2}+V_{f}^{2}-2 V_{i} V_{f} \cos \theta}
$$

To further illustrate the effect of spaceports at the equatorial region, consider the Kennedy Space Centre's Launch Complex 39-A location at 280 north latitude. The Earth's rotational speed at this location is about $1,440 \mathrm{~km} / \mathrm{hr}$. The difference in the Earth's surface speed between the equator and the launch complex is about $229 \mathrm{~km} / \mathrm{hr}$. To compensate for this difference in speed requires an enormous amount of energy (fuel) to accelerate the huge mass of the LV with its fuel and payload (Brown and Harris, 2018). Launching from the equator, however, makes a real difference in terms of launch cost and energy requirements. Moreover, to launch a communications satellite, it will require a speed of $11,300 \mathrm{~km} / \mathrm{hr}$ to maintain an orbital period like that of the Earth. Launches at the equatorial region naturally give a boost of about $1,675 \mathrm{~km} / \mathrm{h}$ out of the $11,300 \mathrm{~km} / \mathrm{hr}$ neglecting atmospheric drag and other factors. The mass fraction of a rocket determines the ratio of the initial mass $(\mathrm{Mi})$ of a rocket including propellant to the final mass (Mf) after burn-out. This ratio gives an idea of the total propellant required for a mission. The rocket's mass fraction of 2.43 with a typical effective exhaust velocity of $10,800 \mathrm{~km} / \mathrm{hr}$ will be required to achieve a change in velocity of about $9,600 \mathrm{~km} / \mathrm{hr}$ to reach the geostationary orbital target according to equation (6) below;

$$
\Delta V=v_{e} \ln \frac{M_{i}}{M_{f}}
$$

Figure 6 Graph of rocket mass fractional change at varying latitude

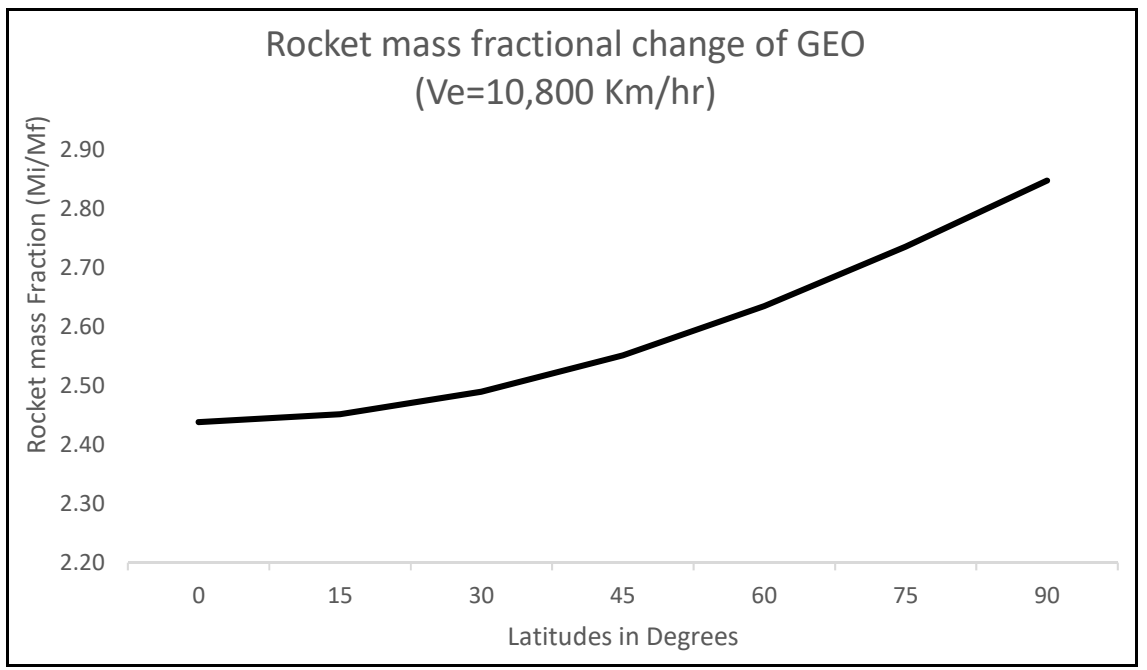


Figure 6 compares the mass fraction required for launches at the equator and the respective latitudes. From the analysis, it is observed that the mass fraction required for the launch of satellites increases as the spaceports' latitude increases. It is therefore beneficial and economical to launch such satellites at the equatorial region where the satellite will require less manoeuvres to be placed at the desired orbit of operation, consuming less propellant and invariably reducing launch cost.

\section{Satellite launch system}

It is imperative to understand the technicalities of a satellite launch system with regards the objectives of this article. Several nations and private space companies have rocket launch facilities for launching satellites of various weights into orbits. It is necessary to understand the launch dynamics and requirement to absolutely know its systems requirement and environmental effects according to launch site location.

There are basic requirements of a spaceport such as the LV assembly facility, the fuel station, launch pad (a movable launch tower, exhaust bucket trench) and the Ground Control station with antennas. The assembly facility enables the integration of the payload (satellite) to the LV and also provides test facilities for rocket motors, ejection system and integration of rocket stages. The fuel station houses the fuel for the LV and other coolants such as nitrogen or water to bring down the temperature of the nozzles during ignition and lift off. The launch pad which consists of the tower and the exhaust trench holds the LV in an upright position after conveying it from the assembly facility on a rail. The tower comprises of elevators for electrical connections, fuelling of the stages and payload boarding in the case of man missions. The ground control station houses the operators and equipment for the control of the LV. For most satellite launches, the scheduled launch rocket is initially aimed vertically. This gets the rocket through the thickest part of the atmosphere rapidly and minimises fuel consumption.

A typical launch sequence consists of the sequences illustrated in Figure 7 by the Russian Cosmodrome. The rocket blasted vertically upward to overcome a greater part of the atmospheric resistance in lower atmosphere just after lift-off, the rocket control mechanism uses the inertial guidance system to make necessary adjustments from the rocket's nozzles to tilt the rocket in the course described in the flight plan. In most cases, the flight plan requires the rocket to head eastward because the Earth rotates in the same direction, giving the LV a free boost. The strength of this boost depends on the rotational velocity of the Earth at the launch location (de Selding, 2016). The boost is greatest at the equator, where the distance around the Earth is greatest and rotation fastest. Some rockets are enhanced with solid fuel boosters to help them overcome the force of atmospheric drag and gravity. Once that has been achieved, there is a stage separation as shown in Figure 7. The rocket boosters or first stage is jettisoned while the remaining vehicle continues with the flight plan. When the rocket reaches extremely thin air, at about $193 \mathrm{~km}$ altitude, the rocket's navigational system fires small rockets (thrusters), just enough to turn the LV into a horizontal position. The satellite is then released. At this point, thrusters are fired again to ensure separation between the LV fairing section and the satellite itself as shown in payload fairing separation. 
Figure 7 A typical rocket launch sequence (see online version for colours)

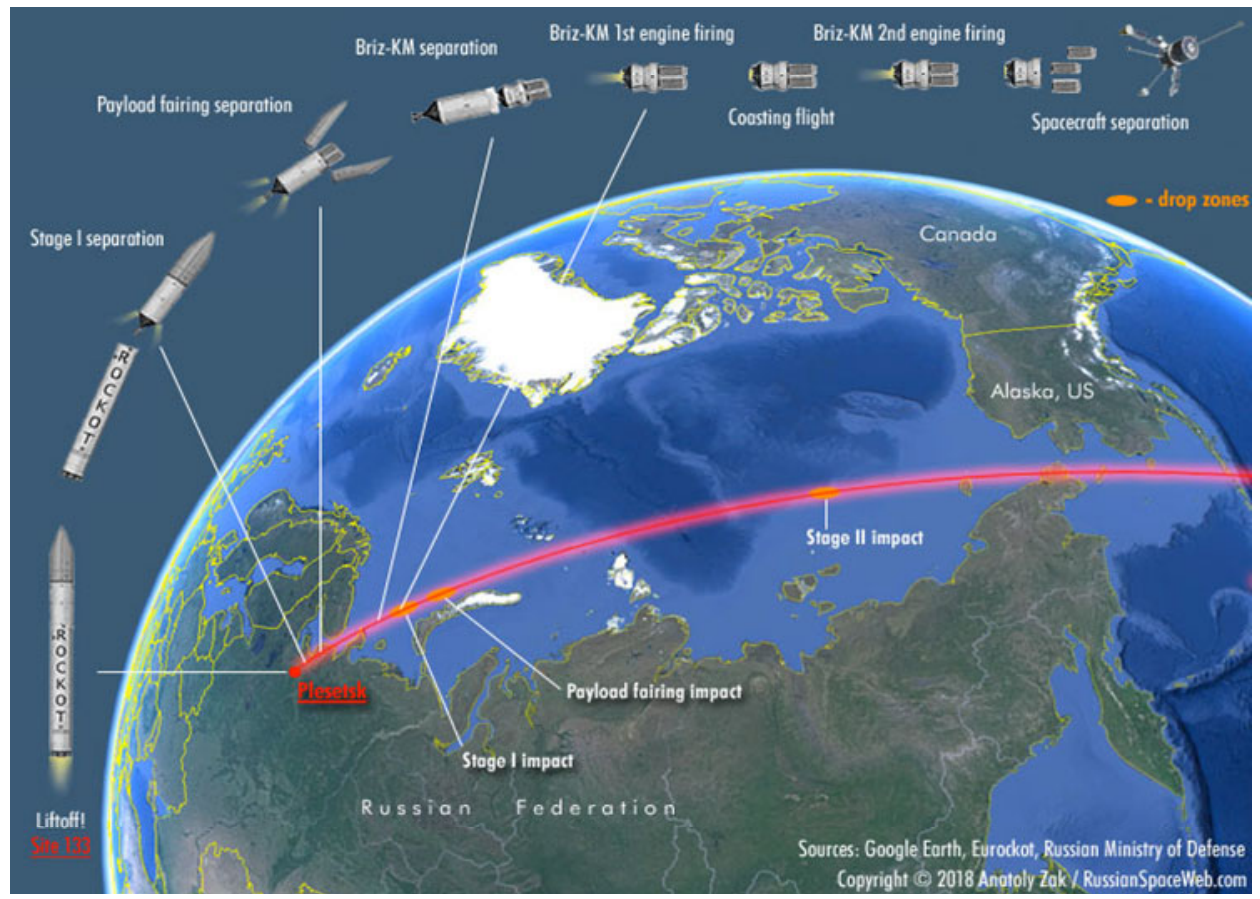

Source: Zak (2019)

A rocket must not always accelerate to at least $40,320 \mathrm{~km} / \mathrm{hr}$ to completely escape the Earth's gravity and fly off into space. However, the Earth's escape velocity is much greater than what is required to place a satellite in orbit. With satellites, the objective is not to escape the Earth's gravity, but to balance it. Orbital velocity is the velocity needed to achieve balance between Earth's gravitational pull on a satellite and the inertia of the satellite motion: the satellite's tendency to keep going (Sellers, 2004). This is approximately $27,359 \mathrm{~km} / \mathrm{hr}$ at an altitude of about $400 \mathrm{~km}$. Without gravity, the satellite's inertia would carry it off into space. Even with gravity, if the intended satellite goes too fast, it will eventually fly away. On the other hand, if the satellite goes too slowly, gravity will pull it back to the Earth. At the correct orbital velocity, gravity exactly balances the satellite's inertia, pulling down towards the Earth's centre just enough to keep the path of the satellite curving like the Earth's curved surface, rather than flying off in a straight line (Sellers, 2004). The orbital velocity of the satellite depends on its altitude above the Earth, the nearer to the Earth, the faster its orbital velocity.

\section{Africa's strategic position for siting a spaceport}

The African continent is nearly equally divided at $35^{\circ} \mathrm{N}$ and $35^{\circ} \mathrm{S}$ by the equatorial line. It has land cover of about 30.3 million square kilometres and is bounded by the Mediterranean Sea in the North, Indian Ocean in the South East and the Atlantic Ocean in the West (WorldAtlas, 2021). The African equatorial plane is a rain forest region 
bounded at the extremes with oceans and suitable for coastal establishment of spaceport considering the natural environmental isolative factors surrounding the continent. The northern part of Africa is mostly a desert area, sparsely populated and can accommodate launch facilities as earlier established by the Western nations. All the factors that are usually considered in siting a spaceport such as the target orbit, flight paths and local weather conditions, population density, and proximity to the equator, airports, seaports are inherent on the African continent.

Space programmes are becoming quite extensive in Africa with several regional and national states developing capacity in space science and technology. Nineteen countries in Africa have national space programs with a growing number of commercial companies developing space technologies and offering services on the continent. Africa has launched three multilateral satellites and 38 unilateral satellites since 1999, with 15 launched in the last four years, indicating an increase in the acceptance of space technology and its potential to drive the continent's growth towards sustainable development and improving the lives of the African people (Space in Africa, 2019b). Space in Africa estimates that by 2024, the total number of African satellites launched into space will be over 90; they also project a likely $40 \%$ growth of the African space industry from $\$ 7$ billion to over $\$ 10$ billion in five years (Space in Africa, 2019b). This clearly shows that leveraging on the benefits of this huge potential, the establishment of a spaceport within the African continent, will accelerate the African Space Leadership Conference (ASLC) agenda for the use of space technology for a sustainable economy, and facilitate the strategic objectives of the African Space Strategy to develop a sustainable and vibrant indigenous space industry that harnesses the potential of space science and technology for socio-economic benefits (African Union, 2019).

With the newly established African Space Agency (ASA), African regional powers, the African Union (AU), established and emerging space faring African nations, promoting an African-led space agenda through mutually beneficial partnerships, a strategic framework for the establishment of the spaceport in Africa is achievable and sustainable.

\section{Prospective locations for siting Africa's spaceport}

Three prospective locations for siting Africa's spaceport are proposed based on preliminary investigations carried out by The National Society for Black Engineers (NSBE) Space Special Interest Group (SIG) in 2012 for establishment of a spaceport in East Africa (Kegege et al., 2016) and the existing rocket launch activities at the Centre for Space Transport and Propulsion Epe Nigeria (Oyewole, 2017).

Manda and Pate Islands in Kenya and Epe in Nigeria offer the best sites for spacecraft launches to GEO, LEO and or interplanetary trajectories due to their near equatorial location and their accessible to the mainland and airports.

A spaceport in Manda or Pate Island is advantageous as they have the ocean to their east in order to minimise the potential hazard of launch failures as shown in Figure 8(a). Similarly, Epe has the Epe Lagoon and the Atlantic Ocean to its advantage as depicted in Figure 8(b). Manda Island is located at latitude $2^{\circ} 15^{\prime} 40.86^{\prime \prime} \mathrm{S}$ and longitude $40^{\circ} 57^{\prime} 2.95^{\prime} \mathrm{E}$, Pate Island at latitude $2^{\circ} 5^{\prime} 55.78^{\prime \prime} \mathrm{S}$ and longitude $41^{\circ} 5^{\prime} 22.53^{\prime}$ 'E and Epe at latitude $6^{\circ} 35^{\prime} 2.83^{\prime \prime} \mathrm{N}$ and longitude $3^{\circ} 59^{\prime} 0.1^{\prime \prime} \mathrm{E}$. The rotational velocities of Epe, Pate and Manda Islands are $460.76 \mathrm{~m} / \mathrm{s}, 464.79 \mathrm{~m} / \mathrm{s}$ and $464.74 \mathrm{~m} / \mathrm{s}$, respectively. Manda 
Island is further from the equator than Pate Island and more accessible to the mainland with an airport located near the new Kenyan Port, Lamu (Kegege et al., 2016).

Figure 8 (a) Pate and Manda Islands, Kenya (Lamu, 2020) (b) Epe, Nigeria (see online version for colours)

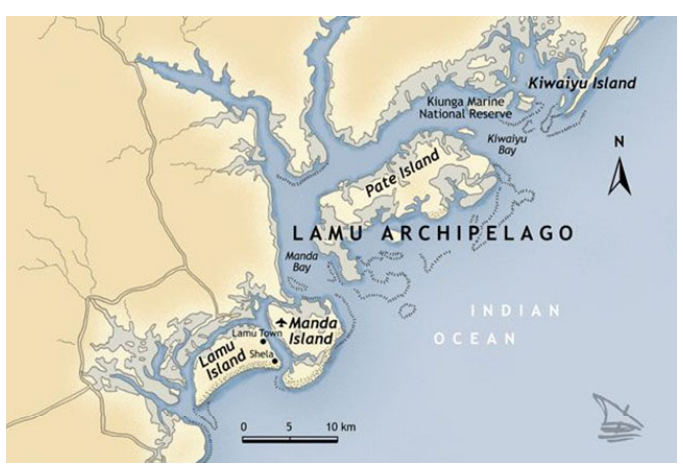

(a)

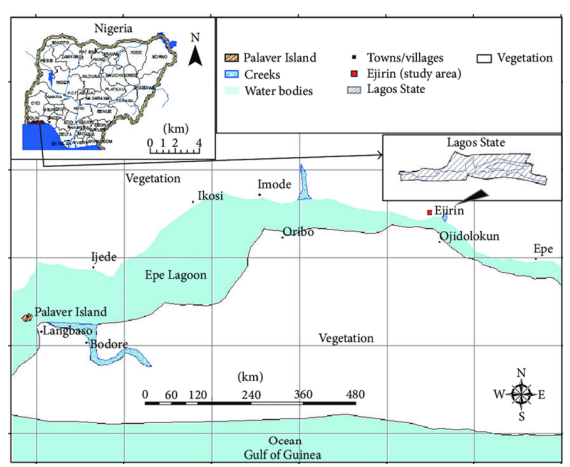

(b)

Source: Inyang et al. (2015)

\section{Feasibility of an implementation strategy for the siting of the African spaceport}

African countries need to make strategic effort towards creating an enabling environment for the establishment of a functional spaceport in Africa. This will equip and empower Africans working in the space sector to develop new technologies and innovate through capacity building thereby creating well-paying employment and entrepreneurship opportunities. In order to achieve this, African countries, especially the emerging space technology nations need to strengthen their existing partnerships among member states for sustainable development. To ensure achievement in space technology development, African member states should deliberately relax specific policies on import duty, tax holidays, regulatory framework and any other sector that would enhance the ease of doing business in order to attract foreign investors in the space industry. Consequently, the ASLC which is an annual meeting of the African space fairing nations and organisations, needs to steer this agenda in the chatter of African Union Governments or the recently adopted ASA which is representing the interest of the African emerging space nations. The European Space Agency (ESA) model can be useful in the establishment of this spaceport and the equity contributions can be shared among member nations. Spaceport launch services are quite beneficial in terms of economic development and social inclusiveness. African equatorial host nations such as Nigeria, Kenya, Ethiopia and Ghana can singularly or wholly establish the spaceport through public private partnership that will be mutually beneficial to all the parties. However, technological regulations and treaties under international regulatory bodies for rockets and ballistic missiles must be registered to ensure peaceful uses of the technology for socio-economic development of the African nations.

The targeted spaceport in Africa may not take-off as a big launch site for large LVs but small rockets for ease of subsystem's transportation and assembly during launch 
campaigns. Some African countries like Nigeria and South Africa have already taken the initiative but efforts need to be increased in terms of political and economic will. Assets of existing inactive launch sites can also be evaluated and revived to function optimally.

\subsection{Model of implementation}

In siting a spaceport in Africa, studies from (Wu et al., 2019, 2020) have facilitated a robust and intelligent implementation strategy for the technical implementation by utilising a control feedback interconnection of a linear time-invariant system and a feedback linearisation multi-input, multi-output (MIMO) invertible nonlinear system. These models can be applied in satellite phasing and alignment, mechanical systems, artificial intelligent systems and autonomous robotic systems.

\subsection{Models of investment}

The following models depict strategies of investment in space ventures that would not necessarily take a toll of the competing resources of African nations.

\subsubsection{Direct funding}

The obvious and direct way for governments to grow in space competence is through direct capitalisation of a program. This funding approach is most appropriate in the case of capabilities for which the government has identified a clear requirement. An example of such an investment is the provision of funds by the Canadian Government for the development of the Canadarm - a robotic arm utilised to move hardware in and out of NASA's Space Shuttle, which was developed from scratch by the Canadian Industry Consortium. The success of this project gave way to Canada becoming the supplier of the robotic Mobile Servicing System which was significant in the International Space Station (ISS) assembly. Presently it is used to manoeuvre supplies and equipment within the ISS (Bryce Space and Technology, 2017).

\subsubsection{Targeted investment}

Targeted investment in abilities with established economic potentials is a broader method. The UK's decision to invest in space for economic growth led to a $25 \%$ increase in its annual investment in ESA in 2013 (Bryce Space and Technology, 2017). Most of the UK's investment flowed back to British Industry as the ESA's geographic return policy enabled proportionate distribution of program work to different member states commensurate to their annual contribution to the agency. The UK's increased funding in the agency yielded fast dividends and facilitated ESA's relocation of its telecommunication directorate from the Netherlands to an existing UK ESA Centre in Harwell. This facility employs about 100 personnel and has contributed significantly to domestic and international industry presence (UK Space Agency, 2017).

\subsubsection{Targeted company investment}

Direct investment in companies developing promising technologies is another approach to targeted investments. In February 2017 Innovation, Science and Economic 
Development Canada, invested about \$17.6 million in UrtheCast, a Canadian Earth Observation satellite company, to support their development of OptiSAR constellation. (PRnewswire, 2017). The Luxemburg Government also set up a fund to support space-mining companies such as Planetary Resources. This initiative started with a memoranda of understanding, then a new pro-developing space-mining law and funding for research and development (de Selding, 2016).

\subsubsection{Private sector investment}

Governments also look to attract private investments through favourable taxation policies and incubators that leverage on non-cash public resources to nurture upcoming industries. The Luxembourg government provides a good example of both. In 2009, Intelsat, one of the top global commercial satellite operators, relocated its corporate headquarters from Bermuda to Luxembourg. The company described its new host as "a stable jurisdiction that is familiar with the fixed satellite services sector and has established tax treaties with the countries in which Intelsat does business" (Bryce Space and Technology, 2017). Luxembourg is also host to Intelsat's competitor SES, which was created by the government in 1985 .

\subsubsection{Public private partnership}

This type of investment is common in the space economy and can be effectively utilised to overcome barriers which can prevent the establishment of viable and valuable commercial space capabilities like high capital requirements, longer development timelines and technology risk (Bryce Space and Technology, 2017). Public-private partnerships can involve co-investment between government industry, government anchor tenancy, and some combination thereof.

NASA's effort to foster commercial cargo and crew transportation for the ISS through co-investment and a guaranteed market for the resulting services is a successful example of such partnership. SpaceX's growing and highly competitive satellite launch business serves commercial and government satellite owners well; while NASA programme is focused on ISS cargo launches, NASA resources have contributed to SpaceX's competitiveness in satellite launch by developing their capability, building and boosting their workforce and infrastructure. The US National Geospatial-Intelligence Agency (NGA) used a similar co-investment tenancy arrangement with DigitalGlobe, an Earth Observation Satellite Operator. This commercial company has built a successful global business and is a vital source of satellite imagery and related products to the US defence and intelligence community. In all these examples, the government remains a significant customer.

Some public private partnerships fail to follow through as intended, noteworthy is Europe's Galileo GNSS satellite programme. This programme originally featured a large financial investment in the ground and application segments from an industrial consortium whose recompence was to be a monopoly operator for the resulting services (de Selding, 2007). However, the Consortium did not meet the goals set by the European Union, thus throwing the entire program into a financial crisis that was resolved when the EU stepped in with fresh funding and took over the programme (Bryce Space and Technology, 2017). 
Public-private partnerships are most successful when the government has a clear understanding of the market for the capability it is seeking to develop, and is prepared to reduce market risk as an anchor customer or with appropriate investment commitments. Government decision-makers benefit from rigorous, independent analysis of market dynamics from sources other than the parties to partnership negotiations. Public-private partnerships are less successful when the government places bets on markets it does not fully understand, and over which it has no control, in an effort to defray its own costs. For countries seeking to build up a domestic space capability, working with established space powers has proven to be a successful pathway. Such international cooperation might take the form of agreements between governments to pursue a specific mission or set of missions. The ISS, of course, is a massive cooperative effort among the world's leading space powers, resulting in a unique space capability as well as creating relationships (generally viewed as positive) that help to shape today's complex geopolitical dynamics (OECD, 2011).

A multi-dimensional model of investment will be advantageous for the African spaceport as it will provide the opportunity for it to ride on the customer base and heritage of its private partners or investors. A multi-dimensional approach that is dynamic, benefits from diversification across many investment strategies and is less susceptible to poor performance consistency (Jacobs and Levy, 2014). It will minimise risk of performance due to changing global economic policies and other market trends; and generate returns by providing several income sources as a result of broadened investment opportunities (Jacobs and Levy, 2014).

\section{Conclusions}

It is obvious from the early ' $60 \mathrm{~s}$ and 70 s that spaceports were strategically signed off from the African shores despite its strategic global location. This development was basically due to the importance and economic potential of the technology in Africa. Africa which is almost centrally divided by the equatorial plane, must take great advantage of locations near as possible to the equator for space launches because of the natural velocity of the Earth, reducing the fuel expended for GEO, LEO and interplanetary missions. The viability of spaceports has gained momentum across the world in recent times because of its economic potential, the emergence of commercial space travel and miniaturisation of satellites and its technologies. Africa can leverage on these potentials and the increasing number of emerging and developing space nations to its benefit to develop a new launch site or upgrade and repair her existing ones, as currently, the African continent is missing space launch, a major component of the space value chain.

A multi-dimensional implementation model of investment is proposed, that harnesses public private partnerships, government direct investment, targeted company investment and private sector investment to achieve a successful and sustainable African spaceport development program. Deliberate policies and tax rebates must be implemented to attract private sector participation in establishing this technology in the African continent. The new ASA should complement the national and regional space programs to facilitate and implement a strategic framework for the revival of existing inactive spaceports and or establishment of a new spaceport on the continent. 


\section{References}

African Union (2019) African Space Strategy for Social, Political and Economic Integration [online] https://au.int/sites/default/files/documents/37434-doc-au_space_strategy_isbnelectronic.pdf (accessed 23 September 2020).

Agboola, O. (2011) 'Space system and engineering in Africa: Nigeria as a case study', African Leadership Conference, Kenya.

Bate, R.R., Muller, D.D. and Whyte, J.E. (1971) Fundamentals of Astrodynamics, Dover Publication Inc., New York, NY.

Bradley, G. (2017) NZ Herald [online] https://www.nzherald.co.nz/business/next-moves-forrocket-lab-following-lift-off-from-mahia/AKYC2GUIT72XQC47MOZWFRRHRQ/ (accessed 17 December 2019).

Brown, G. and Harris, W. (2018) How Satellites Work [online] https://science.howstuffworks.com/ satellite1.htm (accessed 21 December 2019).

Bryce Space and Technology (2017) Global Space Strategies and Best Practices: Research Paper for Australian Government, Department of Industry, Innovation and Science, Australian Government, Sydney.

Caravotas, S. (2019) Denel Overberg Test Range - Africa's Premium Aerospace Test Facility [online] https://oidagroup.com/denel-overberg-test-range-africas-premium-aerospace-testfacility/ (accessed 12 February 2021).

da Cás, P., Veras, C., Shynkarenko, O. and Leonardi, R. (2019) 'A Brazilian space launch system for the small satellite market', Aerospace, Vol. 6, No. 11, pp.2-19.

de Selding, P.B. (2007) SpaceNews: Europe Faces More Government Financing for Galileo Program [online] http://spacenews.com/europe-faces-more-government-financing-galileoprogram (accessed 12 February 2020).

de Selding, P.B. (2016) SpaceNews: Luxembourg taking major stake in Planetary Resources [online] http://spacenews.com/luxembourg-government-to-buy-up-to-49-of-planetaryresources-european-business/ (accessed 12 February 2020).

Greshko, M. (2018) National Geographic: See all the World's Active Rocket Launch Sites [online] https://www.nationalgeographic.com/science/2018/10/news-spaceports-cosmodromes-mapsworld-space-week/ (accessed 17 February 2020).

Ikpaya, I.O. et al. (2017) 'Pursuit of Nigeria into space for sustainable development', in Space Operations: Contributions from the Global Community, pp.233-251, Springer International Publishing AG, Heidelberg, Germany.

Inyang, A., Sunday, K.E. and Nwankwo, D. (2015) 'Composition of periphyton community on water hyacinth (Eichhornia crassipes: in analysis of environmental characteristics at Ejirin Part of Epe Lagoon in Southwestern Nigeria', Journal of Marine Biology, pp.1-9.

Isoun, T. (2008) 'Space landing', Nature, pp.35-35.

Jacobs, B.I. and Levy, K.N. (2014) 'Investing in a multidimensional market', Financial Analyst Journal, Vol. 70, No. 6, pp.6-12.

Kegege, O. et al. (2016) Prospective Development of Uhuru Spaceport [online] https://silo.tips/download/prospective-development-of-uhuru-spaceport (accessed 20 July 2020).

Kimani, J. (2018) Capacity Building in Space Technology for Developing Countries Kenya's Perspective [online] https://www.unoosa.org/documents/pdf/hlf/HLF2018/Pres/6_Kimani Bonn Capacity Building for Developing Countries.pdf (accessed 29 December 2019).

Lamu (2020) Archipelago (Picture) [online] https://za.pinterest.com/pin/157907530655757156/ (accessed 23 July 2020).

Lewis, J. (2010) Arms Control Wonk: Egyptian Ballistic Missile Center [online] https://www.armscontrolwonk.com/archive/202630/egyptian-ballistic-missile-center (accessed 20 January 2020). 
McDowell, J. (2017) Sites [List of Launch Sites] [online] https://www.planet4589.org/space/ sites/index.html (accessed 30 November 2019).

NASA (2014) Public-Private Partnerships for Space Capability Development: Driving Economic Growth and NASA's Mission [online] https:/www.nasa.gov/sites/default/files/files/NASA_ Partnership_Report_LR_20140429.pdf.

NTI (2015) Egypt [online]: https://www.nti.org/learn/countries/egypt/delivery-systems/ (accessed 17 January 2020).

OECD (2011) Space Economy at a Glance 2011 [online] https://www.oecd.org/sti/futures/space/ 48301203.pdf (accessed 25 March 2020).

Oyewole, S. (2017) 'Space Research and Development in Africa', Astropolitics, Vol. 15, No. 2, pp.185-208.

Pike, J. (2011a) Weapons of Mass Destruction (WMD) Hammaguir/Hamaguir [online] https://www.globalsecurity.org/wmd/world/france/hammaguir.htm (accessed 29 December 2020).

Pike, J. (2011b) Weapons of Mass Destruction (WMD) Overberg Test Range [online] https://www.globalsecurity.org/wmd/world/rsa/overberg.htm (accessed 29 December 2019).

Pike, J. (2011) GlobalSecurity.org-Hammaguir/Hamaguir [online] https://www.globalsecurity.org/ wmd/world/france/hammaguir.htm (accessed 26 April 2018).

Poole, R. (2020) African Deception [online] https://reason.com/1978/07/01/african-deception/ (accessed 7 December 2019).

PRnewswire (2017) UrtheCast Reports Second Quarter 2017 Financial Results [online] https://www.prnewswire.com/news-releases/urthecast-reports-second-quarter-2017-financialresults-640381543.html (accessed 29 September 2020).

PRWeb (2012) African Commercial Spaceport a Basis for Regional Economic Growth [online] https:/www.prweb.comeast_african.

Roberts, T.G. (2019) Spaceports of the World, March, Center for Strategic and International Studies, Washington DC.

Robertson, I. (2020) Lamu Kenya (Picture) [online] https://za.pinterest.com/pin/ 157907530655757156 (accessed 23 July 2020).

Robotham, K. (2012) East African Commercial Spaceport a Basis for Regional Economic Growth. [online] https://www.prweb.com/releases/spaceport/east_african/prweb10084538.htm (accessed 12 January 2020).

RP Defense (2011) Denel rebrands OTB [online] http://rpdefense.over-blog.com/article-denelrebrands-otb-70791003.html (accessed 12 February 2020).

Sellers, J.J. (2004) Understanding Space, An Introduction to Astranautics, 3rd ed. McGraw Hills Inc., New York.

Space in Africa (2019a) African Space Industry Annual Report 2019 Edition [online] https://africanews.space/african-space-industry-annual-report-2019-edition/ (accessed 27 January 2020).

Space in Africa (2019b) Kenya and Italy Close in on Signing Ownership Deal in Respect of Luigi Broglio Space Centre [online] https://africanews.space/kenya-and-italy-signing-ownershipdeal-luigi-broglio-space-centre/ (accessed 7 December 2019).

UK Space Agency (2017) UK Space Agency - Corporate Plan, 2017-2018 [online] https:/www.gov.uk/government/uploads/system/uploads/attachment_data/file/641447/ corporate_plan_2017-18.pdf (accessed 21 February 2021).

Umunna, R. and Ovie, E. (2014) 'National Space Programs: Africa's experience', 65th International Astronautical Congress, Toronto, Canada.

Wade, M. (2019) Encyclopedia Astronautica [online] http://www.astronautix.com/o/otrag.html (accessed 6 March 2021).

Wallis, S. (2018) ASPI The Strategist [online] https://www.aspistrategist.org.au/a-sovereignlaunch-capability-for-australia/ (accessed 6 March 2021). 
WorldAtlas (2021) Africa [online] https://www.worldatlas.com/webimage/countrys/af.htm (accessed 13 February 2021).

Wu, Y.Q., Isidori, A., Lu, R. and Khalil, H. (2020) 'Performance recovery of dynamic feedback. Linearisation methods for multivariable nonlinear systems', IEEE Transactions on Automatic Control, Vol. 65, No. 4, pp.1365-1380.

Wu, Y.Q., Lu, Y., He, S. and Lu, R. (2019) 'Synchronisation control for unreliable network systems in intelligent robots', IEEE Transactions on Mechatronics, Vol. 24, No. 6, pp.2641-2651.

Zak, A. (2019) Last Rockot Launches a Satellite Cluster [online] http://russianspaceweb.com/ gonets-block15.html (accessed 21 January 2020). 